\title{
Isolation, Screening, and Characterization of Antibiotic-Degrading Bacteria for Penicillin V Potassium (PVK) from Soil on a Pig Farm
}

\author{
Xuanjiang Yang ${ }^{1,2}$, Miao $\mathrm{Li}^{1, *}$, Panpan Guo ${ }^{1}$, Hualong $\mathrm{Li}^{1}{ }^{1}, \mathrm{Zelin} \mathrm{Hu}^{1}$, Xianwang Liu ${ }^{1}$ and \\ Qiang Zhang ${ }^{3}$ \\ 1 Institute of Intelligent Machinery, Hefei Institute of Material Sciences, Chinese Academy of Sciences, \\ Hefei 230031, Anhui, China; xjyang@mail.ustc.edu.cn (X.Y.); panpan2019520@163.com (P.G.); \\ hlli@iim.ac.cn (H.L.); zlhu@iim.ac.cn (Z.H.); lxw440@163.com (X.L.) \\ 2 Hefei Institutes of Physical Science, Chinese Academy of Sciences, University of Science and Technology \\ of China, Hefei 230026, China \\ 3 Department of Biosystems Engineering, University of Manitoba, Winnipeg, MB R3T 5V6, Canada; \\ Qiang.Zhang@umanitoba.ca \\ * Correspondence: mli@iim.ac.cn; Tel.: +86-189-6181-2279
}

Received: 26 April 2019; Accepted: 10 June 2019; Published: 19 June 2019

\begin{abstract}
Background: Antibiotics are frequently used on farm animals, making animal husbandry a relatively large source of antibiotic pollution of the environment. The present study aims to isolate and acclimatize antibiotic-degrading bacterial strains for penicillin V potassium (PVK) from the contaminated soil of a pig farm. (2) Methods: Bacterial strains were isolated and acclimatized by continuous enrichment of cultures with PVK as the sole carbon source. The antibiotic susceptibility test, thiol mercury salt ultraviolet spectrophotometry (TMSUS), morphological observations, and 16S rDNA sequence analysis were used to identify and characterize the isolated strains. (3) Results: Four bacterial isolates (denoted as LM-1, LM-2, LM-3, LM-4) were obtained, and two of them (LM-1, LM-2) with the highest degradation rates were identified to belong to the same genera as Bacillus. These two isolates were found to be resistant to PVK antibiotic in an antibiotic sensitivity test. The TMSUS indicated that the strains LM-1 and LM-2 had good performance in PVK degradation (68\% for LM-1, $66 \%$ for LM-2 in $48 \mathrm{~h}$ ) when the initial PVK concentration was about $100 \mu \mathrm{g} / \mathrm{mL}$. (4) Conclusions: Two bacterial strains isolated from the soil on a pig farm are effective in degrading PVK and can be potentially used for bioremediation of PVK antibiotic-contaminated soils.
\end{abstract}

Keywords: penicillin; biodegradation; soil; pig farm; bacterial isolate; Bacillus

\section{Introduction}

Intensive livestock farming has been identified to be associated with extensive usage of antibiotics contained in pharmaceuticals that are widely produced and applied to treat bacterial infections in humans and livestock [1-3]. The use of antibiotics in livestock production is forbidden in some regions in the world, (e.g., the European Union since 2006) because of the overuse, and misuse or lack of control in administering antibiotics, resulting in the accumulation of antibiotics in animal products and the environment $[4,5]$. Research has shown that the spread of multidrug resistant bacterial strains and their potential adverse effects on animals and environment are closely associated with the abuse of antibiotics [6,7]. Numerous studies have reported the detection of antibiotics in coastal water and wastewater at concentrations from $\mu \mathrm{g} / \mathrm{L}$ to $\mathrm{mg} / \mathrm{L}$ levels [8]. Furthermore, antibiotic resistant genes harbored by mobile genetic elements have proven to be transferred between bacteria and the 
environment $[9,10]$. The potential epidemiological risks to human health triggered by horizontal antibiotic resistant gene transfer will increase with antibiotic resistance proliferation.

A group of commonly used antibiotics that attack a wide range of bacteria are penicillins, such as penicillin $\mathrm{V}$ potassium (PVK), which is a slow-onset antibiotic that is useful for the treatment of a number of bacterial infections. Although it is less active than other drugs, like penicillin $G$, against Gram-negative bacteria, PVK is more acid-stable than natural penicillins, allowing it to be taken orally without being decomposed by gastric acid. Furthermore, PVK is designed to have a good hydrolysis-resistant capability to strengthen the stability in treating bacterial infections [11]. Substantial concentrations of PVK have been found in livestock manure, soil, and wastewater effluents, which may pose potential threats to human health and contribute to the emergence of penicillin-resistant bacterial strains. Therefore, it is imperative for researchers to find ways to degrade the residues of PVK in the environment.

Various methods have been explored to remove penicillin antibiotics from wastes, including chemical hydrolysis, membrane separation, activated carbon adsorption, and photodegradation. However, there are a number of drawbacks associated with these methods, including the formation of secondary toxic byproducts and high operational costs, when using the conventional physical and chemical techniques [12]. Biodegradation may provide alternative tools to degrade antibiotics in wastes. Zhao et al. [13] reported that a highly chelate coccus PC-2, which could use penicillin sodium as the sole carbon source, was screened and separated from the compost materials containing penicillin bacteria residues mixed with pig manure. Adel et al. [14] reported that significant degradation of cephalexin antibiotics was produced by the Bacillus subtilis strain. Al-Gheethi et al. [15] investigated the biodegradation by Bacillus subtilis of four $\beta$-lactam antibiotics (amoxicillin, ampicillin, cefalexin, cefuroxime) and found that Bacillus subtilis treatment was especially efficient for removing amoxicillin, ampicillin, and cefalexin at a concentration of $1 \mathrm{mg} / \mathrm{L}$, with removal rates up to $25.03 \%, 22.59 \%$, and $10.62 \%$, respectively.

The goal of this study is to find bacteria, naturally existing in soil for degradation of antibiotics. The specific objectives are to: (1) Isolate and characterize bacteria form soil on a pig farm for degradation of PVK, and (2) evaluate the effectiveness of the isolated bacterial strains. PVK was selected in this study not only because it is a class of penicillin antibiotics that are extensively used in both livestock production and human infection treatment, but also due to its chemical structure-PVK may serve as the sole carbon and energy source for the bacterial isolates, which can be identified and characterized by using phylogenetic analysis of $16 \mathrm{~S}$ rDNA sequences.

\section{Materials and Methods}

The enrichment and acclimatization method was used for isolating and screening PVK-degrading bacterial strains. The isolated bacterial strains were then quantitatively evaluated for their effectiveness in degrading PVK by using the thiol mercury salt ultraviolet spectrophotometry (TMSUS). The selected high-performance strains were then identified by $16 \mathrm{~S}$ rRNA gene sequencing and phylogenetic analysis. The laboratory approach used in this study was similar to those reported in the literature, such as Liu [16] and Feng [17], which have been proven to be reliable in screening the antibiotic-degrading bacterial strains.

\subsection{Collection of Soil on Pig Farm}

Soil extracts were collected from a pig farm in Hefei, China. This farm was selected because there were PVK residuals in the soil from pig manure, which naturally led to the emergence of bacteria that feed on PVK. A total of $1000 \mathrm{~g}$ of soil was gathered from the east, south, west, north sides, and the center of the farm. Collected soil was placed in sealed sterile bags and kept at a temperature above $-20{ }^{\circ} \mathrm{C}$ before the experiment. 


\subsection{Reagents and Culture Media}

The target antibiotic, penicillin $\mathrm{V}$ potassium (PVK, purity $\geq 99.0 \%$ ) used in this study, was purchased from Sigma-Aldrich (St. Louis, MO, USA). Boric acid (analytical purity $\geq 98.0 \%$ ), Ni-acetonitrile (chromatographic purity), Ni-acetic anhydride (analytical purity $\geq 99.0 \%$ ), hydrochloric acid (analytical purity $\geq 99.0 \%$ ), sodium hydroxide (analytical purity $\geq 99.0 \%$ ), imiparzole (analytical purity $\geq 99.0 \%$ ) were purchased from a commercial source (Bangzhili Co., Ltd., Hefei, China). The Luria-Bertani (LB) medium used for enrichment of the bacterial strains contained $\mathrm{NaCl}(5 \mathrm{~g} / \mathrm{L})$, yeast extract $(5 \mathrm{~g} / \mathrm{L})$, and tryptone $(10 \mathrm{~g} / \mathrm{L})$ at $\mathrm{pH}$ 7.0. The mineral salt medium (MSM) used for acclimatization of bacteria strains contained $0.45 \mathrm{~g} / \mathrm{L} \mathrm{KH}_{2} \mathrm{PO}_{4}, 0.1 \mathrm{~g} / \mathrm{L} \mathrm{MgSO}_{4} \cdot 7 \mathrm{H}_{2} \mathrm{O}, 1.79 \mathrm{~g} / \mathrm{L} \mathrm{K}{ }_{2} \mathrm{HPO}_{4}$ per liter, $100 \mu \mathrm{g} / \mathrm{mL}$ PVK . The PVK solution was added to the MSM as the sole carbon source. The LB agar medium used for isolating PVK-degrading bacteria was prepared by adding $1.5 \%(w / v)$ agar powder in the LB medium. All media were autoclaved at $121^{\circ} \mathrm{C}$ for $15 \mathrm{~min}$.

\subsection{Enrichment and Acclimatization of Bacterial Strains}

Enrichment of the bacterial strains was carried out through a series of dilution and incubation. First, one gram $(1 \mathrm{~g})$ of collected soil was suspended in $9 \mathrm{~mL}$ of sterile distilled water and agitated for one minute. This homogenized soil extract solution was then diluted by adding $1 \mathrm{~mL}$ of the solution to $9 \mathrm{~mL}$ of sterile purified water, and the process was repeated six times to achieve a $10^{6}$-fold dilution. One milliliter of the diluted solution was then added to $49 \mathrm{~mL}$ of sterile LB medium containing $20 \mu \mathrm{g} / \mathrm{mL}$ PVK antibiotic as the sole carbon source, incubated at $30^{\circ} \mathrm{C}$, shaken at $150 \mathrm{rpm}$ for 6 or 7 days until an optimal optical density (OD) is reached.

The cultures were then exposed to gradually increased PVK concentrations (40 to $100 \mu \mathrm{g} / \mathrm{ml}$ ) to acclimatize the bacterial strains to PVK antibiotic. Specifically, $2 \mathrm{~mL}$ of enriched culture medium was transferred to the first flask containing $48 \mathrm{~mL}$ of LB medium with $40 \mu \mathrm{g} / \mathrm{mL}$ of PVK; then $3 \mathrm{~mL}$ of the solution was transferred from the first flask to a second flask containing $47 \mathrm{~mL}$ of LB medium with $60 \mu \mathrm{g} / \mathrm{mL}$ of PVK; next, $4 \mathrm{~mL}$ of solution was transferred from the second flask to a third flask containing $46 \mathrm{~mL}$ of LB medium with $80 \mu \mathrm{g} / \mathrm{mL}$ of PVK; and finally $5 \mathrm{~mL}$ of solution was transferred from the third flask to a fourth flask containing $45 \mathrm{~mL}$ of LB medium with $100 \mu \mathrm{g} / \mathrm{mL}$ of PVK. The above transfers were performed at 4-day intervals. In other words, the bacterial strains were given 4 days to acclimatize to each PVK concentration from 40 to $100 \mu \mathrm{g} / \mathrm{mL}$ [18]. The purpose of acclimatization was to obtain bacterial strains with high tolerance and degradation ability to PVK antibiotics.

\subsection{Isolation and Purification of Enriched Bacterial Strains}

Isolation and purification were performed after enrichment and acclimatization. Specifically, the solution from the final flask of acclimatization was serially diluted with sterile distilled water for three times (i.e., 1:1000 dilution), spread onto the LB agar medium, and incubated at $30{ }^{\circ} \mathrm{C}$ for $48 \mathrm{~h}$. A streak plate method was used to carry out the separation and purification of the bacteria, with the specific operation steps outlined as follows: (i) An inoculating loop was used to transfer the bacterial culture onto the LB agar medium to perform a four-line streak on the plate. Specifically, moving the inoculating loop backward on the medium surface to allow the culture solution on the inoculation loop to gradually dilute and disperse along the pre-drawn lines on the medium surface; and (ii) a single cell was then cultured and each cell grew into a colony. The above steps were repeated three times to obtain pure cultures.

\subsection{Qualitative Screening of PVK-Degrading Bacteria}

To qualitatively determine if an isolated bacterial strain was capable of degrading PVK, a piece of filter paper containing $10 \mu \mathrm{g}$ of PVK was applied to the surface of the agar which had been inoculated with a bacterial strain. As the diffusion distance of PVK in the agar increased, the PVK concentration decreased logarithmically to a certain concentration below which the bacterium would not grow, thus 
forming a transparent antimicrobial circle on the filter paper. The size of this inhibition zone reflected the sensitivity of the test bacteria to PVK, i.e., the smaller the circle, the more effective the bacterium is in degrading PVK.

\subsection{Qquantitative Evalatution of PVK-Degrading Bacteria}

The isolated bacterial strains that had shown the ability of degrading PVK in the above-discussed qualitative screening were further evaluated quantitatively for their effectiveness by using the thiol mercuric salt UV spectrophotometry (TMSUS) [17]. Specifically, the purified strains were inoculated on an LB medium containing $100 \mu \mathrm{g} / \mathrm{mL}$ of PVK in a shaker culture at a dose of $1 \%$, and the concentration of survived PVK in the medium was measured by TMSUS in $48 \mathrm{~h}$.

The two key steps in TMSUS measurement were: (i) To find the maximum detection wavelength for PVK, and (2) to establish a standard curve to correlate the PVK concentration to the measured absorbance value. To determine the maximum detection wavelength, $25 \mathrm{~mL}$ of PVK solution of $100 \mu \mathrm{g} / \mathrm{mL}$ was prepared in a $50 \mathrm{~mL}$ volumetric bottle. Following the procedure described in [18], the absorbance was measured in the range from 310 to $340 \mathrm{~nm}$. When a peak appeared, the scan gradient was narrowed in the wavelength range around the peak to find the exact maximum absorption wavelength. The measured result is shown in Figure 1 and it was found that the maximum detection wavelength was around $325 \mathrm{~nm}$ for PVK, which is consistent with the range of 324 to $345 \mathrm{~nm}$ reported in the literature for the maximum absorption of penicillin antibiotics $[17,19]$.
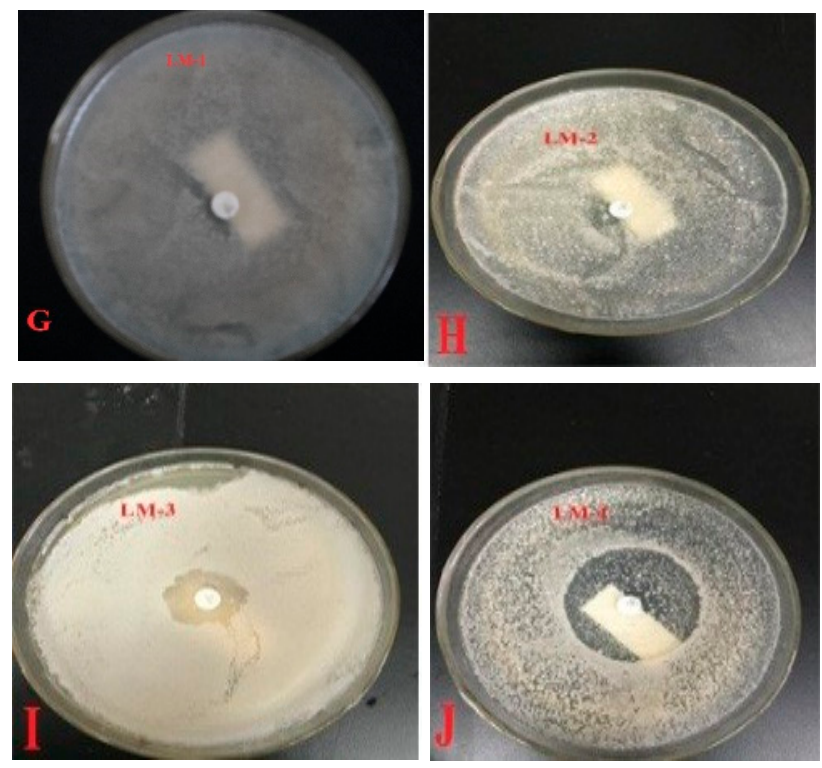

Figure 1. Results of penicillin V potassium (PVK) susceptibility test. G: LM-1; H: LM-2; I: LM-3; J: LM-4.

To establish the standard curve, PVK solutions with concentrations of $0,15,30,45,60,75$, and $90 \mu \mathrm{g} / \mathrm{mL}$ were prepared and the absorbance of PVK was measured at the maximum absorption wavelength $(325 \mathrm{~nm})$. Distilled water was used as the blank control (0 concentration). There was a good linear relationship between the PVK concentration and the absorbance value. The regression equation of the standard curve was determined to be $Y=0.006 \mathrm{X}-0.001$, with $R^{2}=0.998$, where $\mathrm{Y}$ is the absorbance and $\mathrm{X}$ is the PVK concentration in $\mu \mathrm{g} / \mathrm{mL}$.

\subsection{Morphological Observation of Isolated Strains}

Gram staining was used to observe the morphology of the isolated bacterial strains as a means of preliminary identification, following the method reported in [20]. The observed morphological features included color, opaqueness, and surface texture of the bacterial colony. These features would help visual identification of bacterial strains. 


\subsection{Gene Sequencing and Phylogenetic Analysis of Isolated Strains}

The PVK-degrading isolates were cultivated on the LB agar medium at $30{ }^{\circ} \mathrm{C}$ for $48 \mathrm{~h}$. The culture was used for the amplification of bacterial 16S rRNA gene by PCR. Two universal 16S rRNA gene primers (F27:5'-AGTTTGATCMTGGCTCAG-3' and R1492: 5'-GGTTACCTTGTTACGACTT-3') were employed. Culture samples of $25 \mu \mathrm{L}$ were prepared and each sample was composed of $0.5 \mu \mathrm{L}$ of bacterial culture as the template DNA, $7.5 \mu \mathrm{L}$ of $2 \times$ Taq PCR Master Mix (containing 0.2 U Taq DNA polymerase $/ \mu \mathrm{L}, 250 \mu \mathrm{M}$ of deoxy-ribonucleoside triphosphate (dNTP), $2.5 \mu \mathrm{L}$ of $10 \times$ Buffer with $\mathrm{Mg}^{2+}$ (Takara, Tianjin, China), $0.5 \mu \mathrm{L}$ of primer $(10 \mu \mathrm{M})$, and $19.8 \mu \mathrm{L}$ of double-distilled $\mathrm{H}_{2} \mathrm{O}$. The PCR procedure was carried out as follows: Primary denaturation at $94{ }^{\circ} \mathrm{C}$ for $4 \mathrm{~min} ; 30$ cycles of denaturation at $94{ }^{\circ} \mathrm{C}$ for $45 \mathrm{~s}$; annealing at $55^{\circ} \mathrm{C}$ for $45 \mathrm{~s}$; and extension at $72{ }^{\circ} \mathrm{C}$ for $60 \mathrm{~s}$; and an additional reaction for $10 \mathrm{~min}$ at $72{ }^{\circ} \mathrm{C}$. The PCR products were detected on $1.5 \%$ agarose gel to confirm its purity and size. The PCR products were sent to Tiangen Biotech (Beijing, China) for sequencing.

The 16S rRNA gene sequences were compared with other 16S rRNA gene sequences available in Genbank by using the Basic Local Alignment Search Tool (BLASTN) program and aligned with similar sequences by using multiple sequence alignment software [21].The phylogenetic tree was constructed by applying the neighbor-joining method using Molecular Evolutionary Genetics Analysis (MEGA) 7.0 program based on Kimura-2 parameters with 1000 replicates of bootstrap values [22].

\section{Results and Discussion}

\subsection{Isolation and Initial Screening of PVK-Degrading Bacteria}

A total of four PVK-degrading bacterial strains (LM-1, LM-2, LM-3, LM-4) were isolated from the soil collected on the pig farm. All the isolates were first subjected to preliminary screening which was carried out through antibiotic susceptibility tests against PVK. The inhibitory zone diameters of LM-1, LM-2, LM-3, and LM-4 were $12.42 \pm 1.58 \mathrm{~mm}$ (mean \pm standard deviation, SD), $18.37 \pm 3.01 \mathrm{~mm}$, $16.32 \pm 1.06 \mathrm{~mm}$, and $35.61 \pm 1.53 \mathrm{~mm}$, respectively (Figure 1). The inhibitory zone diameter of LM-4 was significantly larger than that of the other three strains (LM-1, LM-2, and LM-3) $(p<0.05)$, and there were no statistically significant differences among LM-1, LM-2, and LM-3. Therefore, LM-4 was considered to be not effective in degrading PVK, and the other three bacterial strains were subjected to quantitative evaluation of TMSUS.

\subsection{TMSUS Measurements}

The measured absorbance values for the three bacterial strains (LM-1, LM-2, LM-3) are summarized in Table 1, along with the blank controls. Using the standard curve $(Y=0.006 \mathrm{X}-0.001)$, these absorbance values were converted to PVK concentrations (survived PVK after exposing to the three degrading strains). Comparing with the corresponding control, it was apparent that all three isolated strains were capable of degrading PVK, with degradation rates of $68 \%$, 66\%, and 38\% for strains LM-1, LM-2, and LM-3, respectively (Table 1). Statistical analysis indicated that the degradation rates of LM-1 and LM-2 were significantly higher than that of LM-3 $(p<0.05)$, while there was no statistically significant difference between LM- 1 and LM-2 $(p>0.05)$. Therefore, LM-3 was de-selected and further analysis was performed to characterize strains LM-1 and LM-2.

Table 1. Measured absorbance values and calculated penicillin V potassium (PVK) concentrations for three isolated strains.

\begin{tabular}{cccccc}
\hline Strains & $\begin{array}{c}\text { PVK Concentration of } \\
\text { Control Group } \\
(\mu \mathrm{g} / \mathbf{m L}, \text { Mean } \pm \text { SD) }\end{array}$ & $\begin{array}{c}\text { OD }_{\text {control }} \\
(\text { Mean } \pm \text { SD) }\end{array}$ & $\begin{array}{c}\text { PVK Concentration of } \\
\text { Test Group } \\
(\mu \mathrm{g} / \mathbf{m L}, \text { Mean } \pm \text { SD) }\end{array}$ & $\begin{array}{c}\text { OD }_{\text {test }} \\
(\text { Mean } \pm \text { SD) }\end{array}$ & $\begin{array}{c}\text { RD } \\
(\text { Mean } \pm \text { SD) }\end{array}$ \\
\hline LM-1 & $96.28 \pm 2.55$ & $0.57 \pm 0.015$ & $33.50 \pm 5.78$ & $0.18 \pm 0.055$ & $0.68 \pm 0.091$ \\
LM-2 & $85.17 \pm 1.67$ & $0.50 \pm 0.021$ & $29.06 \pm 12.62$ & $0.17 \pm 0.076$ & $0.66 \pm 0.14$ \\
LM-3 & $84.61 \pm 12.50$ & $0.51 \pm 0.031$ & $52.94 \pm 4.84$ & $0.32 \pm 0.031$ & $0.38 \pm 0.095$ \\
\hline
\end{tabular}




\subsection{Morphological Features of Isolated Strains}

The colonial morphology of LM-1 strain could be described as follows: White, opaque, circular, wrinkled in surface, and convex in center. The colonial morphology of LM-2 strain was observed as milky white, opaque, circular, and smooth on the surface, and neat in the edge (Figure 2). The morphological features of the two colonies suggested that both LM-1 and LM-2 were Gram-positive bacteria [20]; LM-1 was linearly arranged rods and the LM-2 was dull circles (short but straight) (Figure 2).
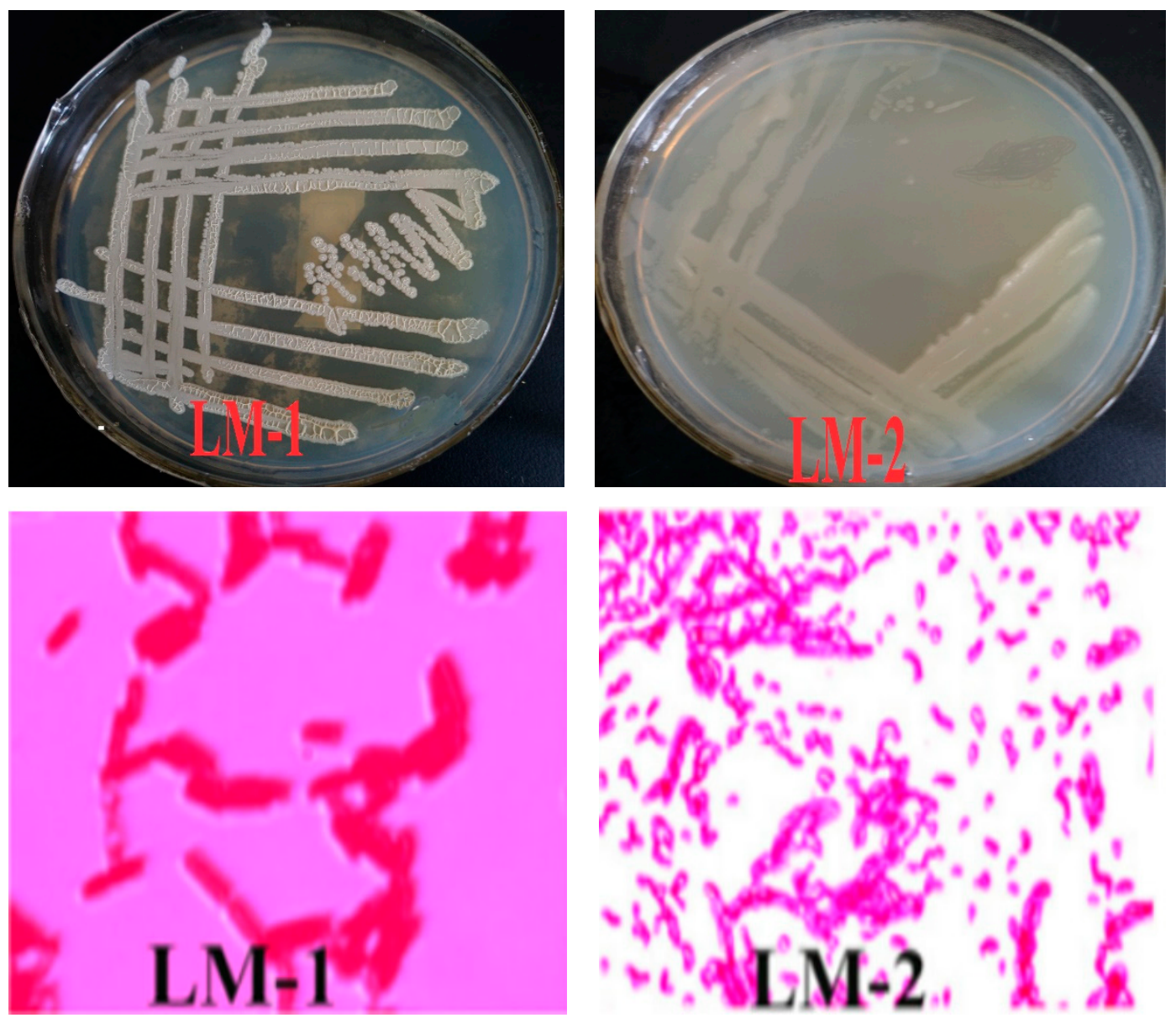

Figure 2. Individual forms of bacterial isolates of LM-1 and LM-2.

\subsection{Gene Sequencing and Phylogenetic Analysis of Two PVK-Degrading Isolates}

The 16S rDNA of LM-1 and LM-2 isolates were amplified using the primers 27F and 1492R, resulting in a characteristic single band of approximately $1490 \mathrm{bp}$ (Figure 3). The isolated strain LM-1 was identified as Bacillus cereus (B. cereus) subgroup on the basis of $16 \mathrm{~S}$ rDNA gene sequencing (Figure 1S in Supplementary Materials) and the phylogenetic tree (Figure 4). The isolated strain LM-2 was identified as Bacillus pumilus (B. pumilus) subgroup on the basis of $16 \mathrm{~S}$ rDNA gene sequencing (Figure 2S in Supplementary Materials) and the phylogenetic tree (Figure 5). The phylogenetic trees of the two isolates clearly demonstrated its evolutionary relationship with a group of $B$. species produced by a neighbor-joining method with the help of MEGA 7.0 program. The closest relative of LM- 1 was B. cereus strain URGRB3 (100\%), and the closest relative of LM-2 was B. pumilus strain RHMR $2(100 \%)$. 


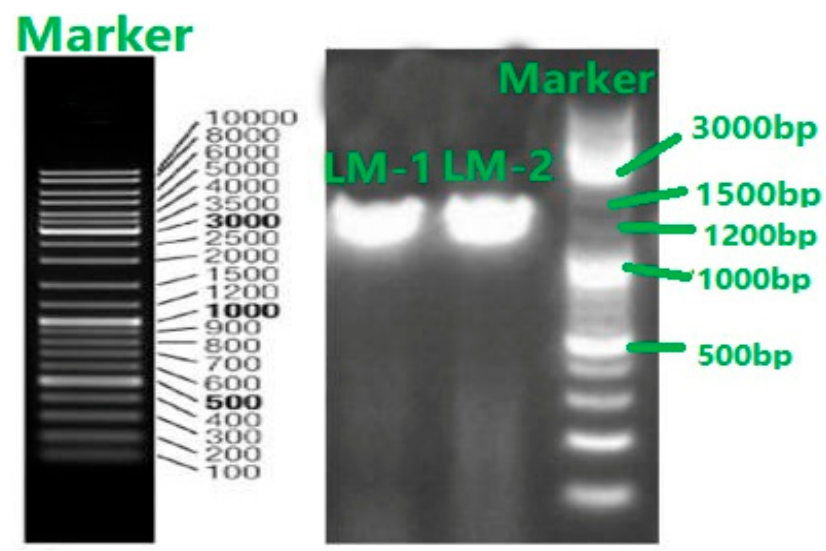

Figure 3. Results of PCR amplification of two bacterial isolates LM-1 and LM-2.

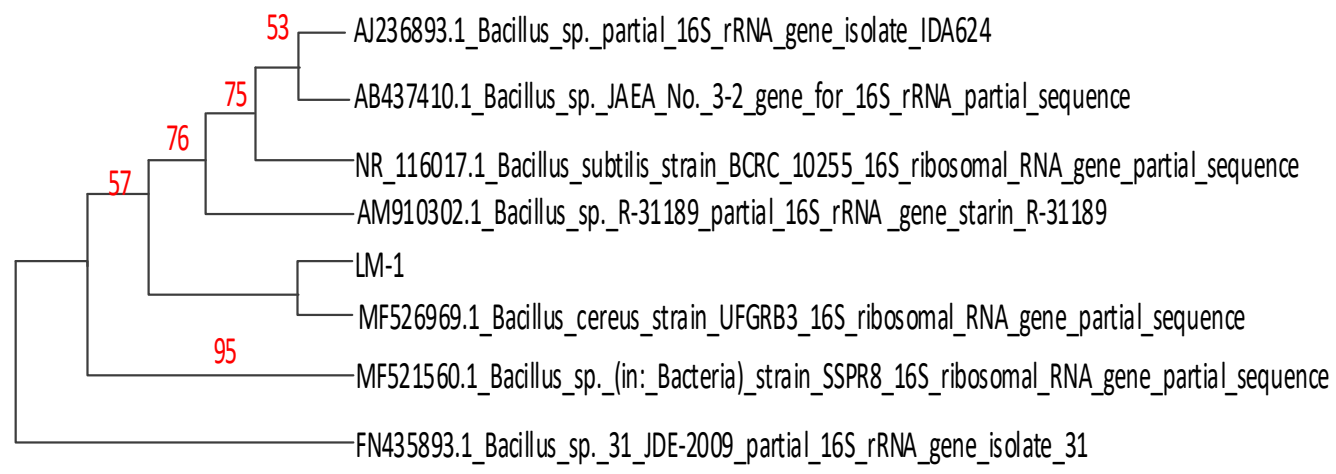

Figure 4. Phylogenetic analysis of isolated strain LM-1 in the neighbor-joining tree.

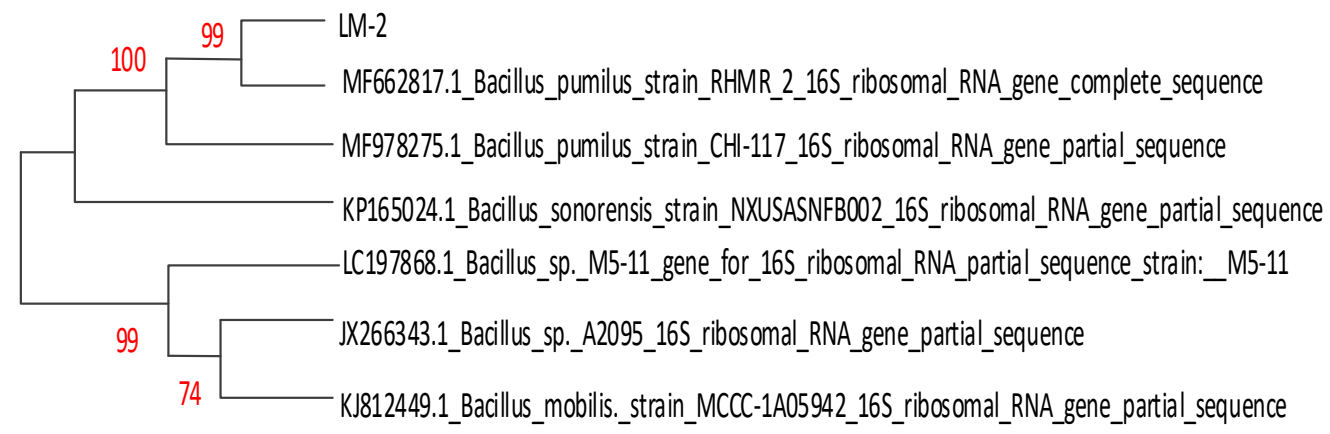

Figure 5. Phylogenetic analysis of isolated strain LM-2 in the neighbor-joining tree.

Both LM-1 and LM-2 belonged to the genus Bacillus, more than 50 species of which have been identified. The genus Bacillus is Gram-positive, and much research has demonstrated the wide distribution of the genus Bacillus in activated sludge, plants, soils, and wastewater [23], which can produce spores that are resistant to adverse conditions. Research has shown that Bacillus can produce antimicrobial substances that inhibit the reproduction of harmful microorganisms and degrade the nutrients in the soil. For example, Peng [24] isolated a strain of Bacillus pumilis 4D-14 from broiler farms, which had strong inhibitory effect on multiple strains of pathogenic bacteria. Yang et al. [25] isolated a strain Bacillus cereus XG1 from the watermelon leaves infected by watermelon bacterial fruit rot and they concluded that the strain XG1 had the potential to be developed as a microbe-herbicide. Wang et al. [26] isolated a Bacillus cereus strain WHY-2 from the deep-sea surface sediments with an effective function of adsorbing thorium ions (Th), which could alleviate the environmental pollution caused by thorium ions as radioactive substances in groundwater.

The antibiotic resistant bacteria play a major role in the microbial degradation of antibiotics. These bacteria can produce corresponding degrading enzymes, which destroy the molecular structure of 
antibiotics by modification or hydrolysis [27]. Several studies (e.g., [28]) have found that antibiotic degrading enzymes mainly include the following four types: $\beta$-Lactamase, aminoglycoside modifying enzyme, macrolide passivase, and chloramphenicol inactivating enzyme, among which $\beta$-Lactamase can destroy the chemical bonds of cephalosporins and penicillins. Furthermore, there are ring-opening oxidases associated with fosfomycin resistance as well as esterases associated with macrolides resistance that can breach the structure of the corresponding antibiotics. Although the degradation mechanisms of PVK was not investigated in this study, it was speculated that the degradation of PVK by LM- 1 and LM-2 isolated in this study was due to the production of $\beta$-Lactamase by the two isolates, which could damage the $\beta$-lactam ring structure of PVK and impel the proceeding of biodegradation.

\section{Conclusions}

Two PVK-degrading bacterial strains (LM-1 and LM-2) were isolated from the soil collected on a pig farm. The two bacterial strains were characterized as belonging to the genus Bacillus. The 16S rDNA sequence comparison indicated that LM-1 and B. cereus strain URGRB3 were members of the same genomic species, so were LM-2 and B. pumilus strain RHMR2. These two bacterial strains extended our knowledge of the list of Bacillus species that could utilize PVK antibiotic as the sole carbon source. LM- 1 could degrade $68 \%$ of PVK-antibiotic in $48 \mathrm{~h}$ at $30{ }^{\circ} \mathrm{C}$ when the initial concentration of PVK was 100 ppm, and LM-2 could degrade $66 \%$ PVK-antibiotic under the same conditions. The strains B. cereus and B. pumilus may have potential for bioremediation of PVK-contaminated environment, such as soil and wastewater, but further research is needed to confirm the performance of these strains in field conditions.

Supplementary Materials: The following are available online at http://www.mdpi.com/1660-4601/16/12/2166/s1, Figure 1S: 16S rDNA sequencing of bacterial isolate LM-1, Figure 2S: 16S rDNA sequencing of bacterial isolate LM-2.

Author Contributions: Conceptualization, M.L. and X.Y.; methodology, X.Y., and H.L.; software, Z.H. and X.L.; formal analysis, P.G.; investigation, X.Y.; writing—original draft preparation, X.Y.; writing—review and editing, X.Y. and Q.Z.; funding acquisition, M.L.

Funding: This work was funded by the State's Key Project of Research and Development Plan of China (Project No. Y821G41591) and the Article Processing Charge (APC) is paid through Project Y821G41591.

Conflicts of Interest: All authors declare that they have no conflict of interest.

\section{References}

1. Carvalho, I.T.; Santos, L. Antibiotics in the aquatic environments: A review of the European scenario. Environ. Int. 2016, 94, 736-757. [CrossRef] [PubMed]

2. Bloem, E.; Albihn, A.; Elving, J.; Hermann, L.; Lehmann, L.; Sarvi, M.; Schaaf, T.; Schick, J.; Turtol, E.; Ylivainio, K. Contamination of organic nutrient sources with potential and treatment options for the production of sustainable fertilizers: A review. Sci. Total Environ. 2017, 607, 225-242. [CrossRef] [PubMed]

3. Ramaswamy, J.; Prasher, S.O.; Patel, R.M.; Hussain, S.A.; Barrington, S.F. The effect of composting on the degradation of a veterinary pharmaceutical. Bioresour. Technol. 2010, 101, 2294-2299. [CrossRef] [PubMed]

4. Gonzalez Ronquillo, M.; Angeles Hernandez, J.C. Antibiotic and synthetic growth promoters in animal diets: Review of impact and analytical methods. Food Control 2017, 72, 255-267. [CrossRef]

5. Vikesland, P.J.; Pruden, A.; Alvarez, P.J.; Aga, D.; Burgmann, H.; Li, X.D.; Manaia, C.M.; Nambi, I.; Wigginton, K.; Zhang, T. Toward a comprehensive strategy to mitigate dissemination of environmental sources of antibiotic resistance. Int. J. Environ. Sci. Technol. 2017, 51, 13061-13069. [CrossRef]

6. Zhou, X.F.; Liu, D.D.; Zhang, Y.L.; Chen, J.B.; Chu, H.Q.; Qian, Y.J. Degradation mechanism and kinetic modeling for UV/peroxydisulfate treatment of penicillin antibiotics. Chem. Eng. J. 2018, 341, 93-101. [CrossRef]

7. Wang, J.; Ben, W.; Yang, M.; Zhang, Y.; Qiang, Z.M. Dissemination of veterinary antibiotics and corresponding resistance genes from a concentrated swine feedlot along the waste treatment paths. Environ. Int. 2016, 92-93, 317-323. [CrossRef] 
8. Wu, M.; Que, C.; Tang, L.; Xu, H.; Xiang, J.J.; Wang, J.J.; Shi, W.Y.; Xu, G. Distribution, fate, and risk assessment of antibiotics in five wastewater treatment plants in Shanghai, China. Environ. Sci. Pollut. Res. Int. 2016, 23, 18055-18063. [CrossRef]

9. Liu, Q.Q.; Li, M.; Liu, X.; Zhang, Q.; Liu, R.; Wang, Z.L.; Shi, X.T.; Quan, J.; Shen, X.H.; Zhang, F.W. Removal of sulfamethoxazole and trimethoprim from reclaimed water and the biodegradation mechanism. Front. Env. Sci. Eng. 2018, 12, 6. [CrossRef]

10. Forsberg, K.J.; Bin, W.; Selleck, E.M.; Sommer, M.O.A.; Dantas, G. The shared antibiotic resistome of soil bacteria and human pathogens. Science 2012, 337, 1107-1111. [CrossRef]

11. Leung, H.W.; Minh, T.B.; Murphy, M.B.; Lam, J.C.W.; So, M.K.; Martin, M.; Lam, P.K.S.; Richardson, B.J. Distribution, fate, and risk assessment of antibiotics in sewage treatment plants in Hong Kong, South China. Environ. Int. 2012, 42, 1-9. [CrossRef] [PubMed]

12. Ben, W.; Qiang, Z.; Pan, X.; Nie, Y. Degradation of veterinary antibiotics by ozone in swine wastewater pretreated with sequencing batch reactor. J. Environ. Eng. 2011, 138, 272-277. [CrossRef]

13. Zhao, J.; Zhang, Z.H.; Duan, H.Y.; Yu, R.; Wang, C.Y. Isolation and identification of a penicillin-degrading strain during composting of penicillin bacteria residue. Res. Environ. Sci. 2016, 29, 271-278. [CrossRef]

14. Adel, A.A.S.; Lalung, J.; Eoman, E.A.; Bala, J.D.; Norli, I. Removal of heavy metals and antibiotics from treated sewage effluent by bacteria. Clean Technol. Environ. Policy 2015, 17, 2101-2123. [CrossRef]

15. Al-Gheethi Adel, A.S.; Ismail, N. Biodegradation of pharmaceutical wastes in treated sewage effluents by bacillus subtilis 1556 WTNC. Environ. Processes 2014, 1, 459-481. [CrossRef]

16. Liu, J.Z.; Wang, Q.; Yan, J.B.; Qin, X.R. Isolation and characterization of novel phenol degrading bacterial strain WUST-C1. Ind. Eng. Chem. Res. 2013, 52, 258-265. [CrossRef]

17. Feng, L.Z. Research on the Biochemical Treatment of Penicillin Wastewater; Northeastern University: Shenyang, China, 2009.

18. Fu, H.; Liu, H.L.; Wang, P. Screening and identification of Penicillin-degrading bacteria and its degradation effects. Environ. Prot. Sci. 2015, 41, 42-45.

19. Liu, N.D.; Lin, G.; Zhang, Q. Determination of benzylpenicillin sodium by the thiol mercuric salt UV spectrophotometry. Chin. J. Hosp. Pharm. 1991, 11, 82-83.

20. Kumar, M.; Leon, V.; Materano, A.D.; Ilzins, O.A. A halotolerant and theromtolerant Bacillus sp. Degrades hydrocarbons and produces tensio-active emulsifying agent. World J Microb. Biot. 2007, 23, 211-220. [CrossRef]

21. Thompson, J.D.; Higgins, D.G.; Gibson, T.J. CLUSTALW: Improving the sensitivity of progressive multiple sequence alignment through sequence weighting, position-specific gap penalties and weight matrix choice. Nucleic Acids Res. 1994, 22, 4673-4680. [CrossRef]

22. Saitou, N.; Nei, M. The neighbor-joining method: A new method for reconstructing phylogenetic trees. Mol. Biol. Evol. 1987, 4, 406-425. [CrossRef] [PubMed]

23. Chen, R.D.; Wu, B.L. Discussion about antibiotic resistance mechanisms. Fujian J. Anim. Husbandary Vet. 2006, 28, 59-60.

24. Yang, J.; Zhang, M.Y.; Zhang, Q.F.; Yang, P.; Liu, Q.W.; Li, Y.G.; Zhang, L.H.; Dong, J.H. Isolation, identification, and herbicidal activity of Bacillus cereus XG1. J. Agric. Univ. Hebei 2016, 39, 81-86.

25. Peng, H.N. Screening and Molecular Identification of Bacteriostatic Bacillus Pumilus 4D-14, Probiotic Development and Application Research; Ocean University of China: Shandong, China, 2013.

26. Wang, W.D.; Lin, W.; Qin, Y.; Zhang, L.K.; Li, J.X.; Li, H.R.; Zhang, T.T. Performance and mechanism of Th (IV) adsorption from aqueous solution by Bacillus cereus WHY-2. J. Chin. Soc. Rare Earths 2018, 36, 746-754.

27. Leng, Y.F. Characteristics and mechanism of Tetracycline Degradation by microorganism; China University of Geosciences (Wuhan): Hubei, China, 2017.

28. Liu, Y.W.; Li, Z.J.; Feng, Y.; Cheng, D.M.; Hu, H.Y.; Zhang, W.J. Research progress in microbial degradation of antibiotics. J. Agro-Environ. Sci. 2016, 35, 212-224.

(C) 2019 by the authors. Licensee MDPI, Basel, Switzerland. This article is an open access article distributed under the terms and conditions of the Creative Commons Attribution (CC BY) license (http://creativecommons.org/licenses/by/4.0/). 